Canadian Journal of Higher Education Revue canadienne d'enseignement supérieur

Volume 48, No. 2, 2018, pages 130 - 148

\title{
Experiences of Food Insecurity Among Undergraduate Students: "You Can’t Starve Yourself Through School”
}

Merryn Maynard

Meal Exchange

Samantha B. Meyer

University of Waterloo

Christopher M. Perlman

University of Waterloo

Sharon I. Kirkpatrick

University of Waterloo

\begin{abstract}
Canadian post-secondary students are vulnerable to food insecurity, yet lack of examination of this issue has prevented identification of policy and program solutions. This mixed-methods study aimed to characterize the experience of food insecurity among undergraduate students by eliciting barriers to food security, strategies used to manage food and money shortages, and perceived implications for health and academic achievement. Surveys and in-depth interviews were conducted with 14 students who demonstrated compromised financial access to food. Students normalized experiences of food insecurity as typical of post-secondary education but expressed anxiety and frustration
\end{abstract}


with financial inaccessibility to healthy food, and described negative implications for their physical and mental health and their ability to perform well in school. Ongoing attempts to adapt or adjust to food insecurity had limited success. Findings highlight the need to challenge the "starving student" ideology, which normalizes the lack of access to healthy food during higher education.

\section{Résumé}

Lesétudiantsdeniveau postsecondairecanadienssontvulnérablesàl'insécurité alimentaire, pourtant ce problème esquive aux examens qui mèneraient aux politiques et programmes solutions. Cette étude aux méthodes mixtes tente de définir l'expérience des étudiants en situation d'insécurité alimentaire en suscitant ses entraves, les stratégies pour gérer les manques de nourriture et d argent, et les impacts perçus sur la santé et la réussite académique. Des sondages et des entrevues ont été menés auprès de 14 étudiants en situation d'insécurité alimentaire. Pour eux, il s'agit d'une expérience normale propre à l>éducation. Mais quant à l'inaccessibilité à une saine alimentation, tous ont parlé d'anxiété et de frustration avec les barrières financières en plus des impacts négatifs sur leur état physique et sur leur performance en classe. Les tentatives courantes d'adaptation à l'insécurité alimentaire ont eu un succès limité. Les résultats démontrent la nécessité de critiquer l'idéologie de " l'étudiant famélique » qui normalise leur accès limité à une saine alimentation durant leurs études postsecondaire.

\section{Introduction}

Food insecurity, which refers to uncertain or inadequate access to food due to financial constraints, is recognized as a serious issue among households in developed countries (Coleman-Jensen, Rabbitt, Gregory, \& Singh, 2015; Tarasuk, Mitchell, \& Dachner, 2012). However, aside from recent research on the clients of campus food banks (Farahbakhsh et al., 2015; Hanbazaza, Ball, Farmer, Maximova, \& Willows, 2016), there has been relatively little examination of this issue in the context of Canadian higher education. Financial strain is a common phenomenon among Canadian students (Burley \& Awad, 2015) and can create vulnerability to income-related shocks that may affect access to food and other basic needs. Several factors likely underlie precarious finances among students, including reduced federal transfer payments to provinces for supporting post-secondary institutions, which has contributed to rising tuition fees over recent years (Harden, 2017; Statistics Canada, 2011). Indeed, tuition fees at Canadian universities rose by $40 \%$ on average from 2006 to 2016 (Statistics Canada, 2016). Expenses associated with education are exacerbated in some regions of Canada by the high costs of rental housing (Burley \& Awad, 2015).

Cross-sectional research in Australia and the United States suggests that food insecurity affects from nearly a fifth to almost two-thirds of students at universities examined (Chaparro, Zaghloul, Holck, \& Dobbs, 2009; Gallegos, Ramsey, \& Ong, 2013; Hughes, Serebryanikova, Donaldson, \& Leveritt, 2011; Maroto, Snelling, \& Linck, 2014; Miles, McBeath, Brockett, \& Sorenson, 2017; Patton-Lopez, Loppez-Cevallos, Cancel-Tirado, \& Vazquez, 2014). Students living in food-insecure households experience poor academic outcomes, 
including lower grade point averages and difficulties concentrating at school, in comparison to food-secure students (Gaines, Robb, Knol, \& Sickler, 2014; Gallegos et al., 2013; Maroto et al., 2014; Munro, Quayle, Simpson, \& Barnsley, 2013; Payne-Sturges, Tjaden, Caldeira, Vincent, \& Arria, 2017). Further, though they did not examine food insecurity in particular, a systematic review by Richardson, Elliott, and Roberts (2013) demonstrates that higher levels of student debt are associated with higher levels of stress among students and a higher likelihood of experiencing poor mental health and depression (Richardson et al., 2013). A recent survey of five Canadian universities conducted by the non-profit organization Meal Exchange suggested that almost two in five students experience food insecurity, with perceived negative impacts on physical and mental health (Silverthorn, 2016).

While in-depth work on student populations is limited, the experience of food insecurity has been conceptualized in other vulnerable groups. Based on evidence collected in Canada and the United States with food-insecure low-income families (Alaimo, 2005; Campbell, 1991; Campbell \& Desjardins, 1989; Rose, 1999), Alaimo (2005) developed a conceptual model identifying four main components characteristic of food insecurity within North American households: anxiety and preoccupation with food due to dwindling household food supplies, inadequate quality of food, insufficient amount or quantity of food available, and an uncontrollable household food supply, resulting in feelings of alienation and, possibly, the "socially unacceptable" acquisition of food through food banks or soup kitchens (Alaimo, 2005). The model identifies financial, socio-environmental, and demographic risk factors that influence a household's ability to adjust to short-term food shortages or adapt to chronic food insecurity over time. It is not known, however, to what extent this model aligns with the experience of food insecurity among post-secondary students.

Further, research on student food insecurity in Canada has yet to incorporate students' lived experiences and perceptions, and has not focused on barriers specific to higher education nor on implications for academic achievement (Farahbakhsh et al., 2015; Hanbazaza et al., 2016). Addressing these gaps is crucial in order to better conceptualize the problem among this population and to inform policy and program actions. Using Alaimo's (2005) conceptual model as a guiding framework, the objective of this mixed-methods study was to shed light on undergraduate students' experiences and perceptions of food insecurity, including the factors that precipitate shortages of food, strategies for managing shortages, and perspectives regarding the impact of food security on health and academic achievement.

\section{Methods}

Recruitment and data collection were conducted between November 2015 and May 2016 at the University of Waterloo. Students were recruited using flyers posted on campus and distributed at the campus food bank. The flyers described the study as an investigation of food access, noted an honorarium of a $\$ 20$ gift card, and included a link to an online screening questionnaire. Criteria for inclusion included enrolment in an undergraduate program for at least 12 months and current enrolment at the university, residing in off-campus housing, being at least 18 years of age, and being fluent in English. Further, students were asked to describe the food situation in their household over the prior 12 months, and were eligible only if they responded that they "sometimes" or "often" did not have enough to eat because they lacked money for food (Bickel, Nord, Price, Hamilton, \& Cook, 2000). In total, 128 students completed the online screening questionnaire 
and 52 were eligible to participate. Theoretical saturation- which occurs when concepts and themes have been sufficiently developed, no new categories are emerging from the data, and discernible relationships between categories can be found (Creswell, 2014)was deemed to have occurred when 14 participants had been interviewed. At that time, recruitment was discontinued. Ethics approval for this study was obtained from the Office of Research Ethics at the University of Waterloo (\#21021). All participants provided written consent and were assigned pseudonyms to ensure confidentiality. Participants completed a single semi-structured interview that queried perceptions and experiences of food insecurity, including perceived contributing factors, strategies for managing food shortages, and perceived implications for health and academic success. The interview guide was informed by prior qualitative research on the experience of food insecurity (Chilton \& Booth, 2007; Connell, Lofton, Yadrick, \& Rehner, 2005; Hamelin, Beaudry, \& Habicht, 2002) and Alaimo's (2005) conceptual model of food insecurity.

Table 1: Selected interview questions to guide discussions of experiences of food insecurity among post-secondary students

Type of Question Question

Icebreaker What is your favourite meal to cook or eat?

Transition What types of foods do you enjoy eating?

Main As a student, what does "having enough food" mean to you?

Main Can you tell me about a time since you've been a student when you didn't have access to enough food or the food that you wanted?

Follow-up Are there other factors that sometimes prevent you from having enough food or the types of food you like and want besides money?

Main Question I'd like to talk to you more about the kinds of things you might do when you are running out of money for food. Can you tell me about some of the things you might do/did when you ran out of food?

Interviews were recorded electronically and transcribed verbatim. Data collection and analysis took place simultaneously, with insights from early interviews prompting revisions to the interview guide to explore emerging topics. Transcripts were coded using NVivo (QSR International, version 10). Thematic analysis followed Layder's (1998) adaptive theory, whereby data were coded deductively using Alaimo's (2005) conceptual model and existing literature, as well as inductively to allow for the emergence of novel themes. Segments of interview text were tagged and labelled according to existing theoretical concepts and new ideas through provisional coding, while common codes were grouped into categories to identify emerging patterns during satellite coding (Layder, 1998). Interview notes were incorporated during provisional and satellite coding and the identification of core categories (Layder, 1998). As codes and categories became more refined with additional interviews, there was movement among the raw data, provisional codes, and core categories to develop broader themes. 
The interview was preceded by the completion of a short survey, including questions on demographic characteristics (age, gender, year of study, international/domestic student status, enrolment in a cooperative education program, sources of financial support, living situation, and use of the campus food bank), as well as perceived physical and mental health and stress, using items adopted from the 2011 Canadian Community Health Survey mental health module (Statistics Canada, 2013). Descriptive statistics were tabulated in Excel. Responses to the survey informed probing questions during the interview and incorporated data into the analysis of the interview using the constant comparative process and framework matrices in NVivo, allowing for comparison of food security experiences across groups (e.g., international versus domestic students, users and non-users of the campus food bank).

Following the interview, the 10 adult-referenced items from the Household Food Security Survey Module (HFSSM) were administered. The HFSSM is widely used in food security research (Bickel et al., 2000; Tarasuk et al., 2012) and queries indicators of inadequate quality or quantity of food within a previous 12-month period due to financial constraints. According to Health Canada coding guidelines, responses to the HFSSM items were used to classify each participant as living in a food-secure household (no positive responses) or a household with marginal (one positive response), moderate (two to five positive responses), or severe food insecurity (six to 10 positive responses) (Health Canada, 2007). These data provided context for the qualitative results.

\section{Results}

\section{Demographic and Health Characteristics}

Participants included eight females and six males who ranged in age from 19 to 25 years and were at various stages of their undergraduate degrees (ranging from year two to four). Half $(n=7)$ were enrolled in a cooperative education program (which provides opportunities for paid relevant work during the completion of a degree), and three identified themselves as international students. Participants most commonly reported financial support from part-time employment $(n=9)$ and family $(n=9)$, but also reported personal savings $(n=8)$ and government student loans $(n=6)$ as other sources of financial support. All but one participant lived with roommates; six reported sharing household costs such as groceries or utility payments with their roommates. Seven participants reported visiting the campus food bank at least once. Most participants reported their general health and mental health as "good" or "very good" ( $n=10$ and 11, respectively). However, the majority either reported their physical health as "fair" $(n=6)$ or "poor" $(n=3)$. Most students $(n=12)$ reported that their average day was "a bit stressful" or "quite stressful."

\section{Household Food Security}

Responses to the HFSSM items were consistent with the descriptions of experiences of food insecurity shared during the interviews. One participant lived in a household with marginal food security over the past 12 months, six lived in households that had experienced moderate food insecurity, and four lived in households characterized by severe food insecurity. Three participants did not complete the HFSSM items, but nonetheless described experiences indicative of food insecurity during their interviews. 


\section{Experiences of Food Insecurity}

In the interviews, several common themes emerged, characterizing students' experience of food insecurity as complex and uncertain, and as requiring constant and ongoing management. This was illustrated by reported compromises in food quality and quantity, preoccupation with food supply, a desire for independence and control over the food situation, feelings of stigmatization, and attempts to normalize the experience.

\section{Compromises in Quantity and Quality of Food}

In the face of money shortages, students attempted to adapt by compromising their food intake. For example, Kiara said, "I'll just change my schedule so I'll sleep in more. So, I'll miss some meals," and Vivian said, "Sometimes I just go to sleep hungry." Students also indicated they routinely ate foods they perceived as being of poor quality, such as low-cost, energy-dense, frozen or canned, and old or unsafe foods. A common trend was students eating whatever would fill them up, regardless of health or nutrition. Isabel talked about buying bagels from the Tim Hortons on campus when she was running out of money for food, because they were "on the cheaper end [and] sort of filling," and avoided buying a salad because "it won't really fill me up," while Aryan talked about purchasing bags of chips during times of food insecurity, because "chips fill you up more."

\section{Preoccupation with the Food Supply}

The ways in which students discussed food revealed a preoccupation with food acquisition and careful consideration about what to buy. For example, Riya felt concerned about trying to purchase food with little money, and explained, "You're just like, 'Oh my god, I have this sort of amount of money, what's the best place I can go." Some had practised memorizing prices and foregoing foods they felt they could not afford. For example, Isabel explained, “Just buying milk or something, I feel like it's splurging for some reason. 'Cause it's so expensive."

\section{Desire for Independence and Control}

Students expressed a strong desire for independence and control over their financial situation. This resulted in avoidance of asking their families for help, even when money ran low. Isabel explained, "[My parents] have so much going on with, like, supporting my brother...I'm trying to not burden [them]," while Aaron said, "I could just ask [my parents] for more money you know, but it's not something I wanna keep relying on all the time." Sophia said, "I feel very guilty 'cause I feel like, at this point in my life, I should have this figured out." Guilt emerged when students did ask for help from family. Myra explained, "I'll let my parents know, they'll come and give me money or they'll transfer money to my account but then I'll feel so bad."

In line with the desire for control, students expressed guilt and regret for spending money on items other than food at certain times, such as the beginning of their university careers or the start of the year as part of their efforts to fit in. For example, Kelly said, "I think I'll definitely get better at [budgeting]. I definitely spent more than I should have at the beginning of the semester on...stuff that you don't really need." 


\section{Stigma and Social Exclusion}

Students directly expressed feelings of stigma and shame associated with food insecurity, particularly when accessing the campus food bank. Vivian said, "I don't really want people to know. So, like, whenever I go to the food bank, I kind of make sure there's nobody around and then I go in." Parth explained that the food bank volunteers are "trying to help, but I'm also feeling inferior" and "I don't think I deserve that food." Students who had not accessed the food bank also discussed stigma. For example, Kelly said, "I don't think it's like a stigma attached to [food bank use]," but went on to state, "You never really want to admit that you need help." Similarly, Isabel stated, "They say it's anonymous, but I feel like it's kind of embarrassing to go there."

Feeling isolated was also part of the experience of food insecurity. For example, Liam explained that his experience of food insecurity while trying to access student loan money was "mostly just frustrating, because I don't know who to turn to." Parth said, "I felt in a void a little bit because I didn't have the money or the means to buy the foods that I like." Students felt pressured to spend money on food in social settings, such as eating out at restaurants or going to bars, and described feeling excluded because they could not afford to participate in these types of activities. Riya described how it felt when her friends wanted to go out to eat:

If you're with other people and...you make a group decision to go somewhere, it's just like that awkward situation where you're like oh, like, what should I say? Should I tell them?... Typically, [you] just tend to keep it to yourself.

\section{Normalizing the "Starving Student" Experience}

In discussing their food situations, students appeared to identify with the norm of the "starving student," viewing reliance on poor-quality foods and food shortages as a typical part of the student experience. As Kelly explained:

There's just sort of this idea that it's okay to eat junk food or food that isn't good for you...the typical, like, "freshman 15." And then everyone's eating Kraft Dinner and Mr. Noodles. And so you kind of feel like it's okay.

Normalizing the experience extended to some participants' notion that they simply needed to adapt to their financial circumstances. For example, Aaron stated, "[Running out of money for food is] just something you get used to, right?" and Parth said that experiencing insufficient finances was "a part of growing up." Participants also made comparisons between their situations and those of others, noting that things could be worse and minimizing the extent of the problem. For example, Parth stated, "I'm still thankful, I have a lot more than other people," while Liam noted how much more difficult it would be if he did not have a place to live, "Looking for a job [while] living on the streets...I can't even imagine having to deal with that." This sentiment was also expressed by students who accessed the campus food bank; as mentioned above, despite needing to access the campus food bank, Parth explained, "I don't think I deserve that food." Some students expressed that they did not need the assistance and did not want to abuse the service. For example, Kelly explained, “I just didn't really consider myself someone that should 
be using that resource," and said, "You don't want to take from someone else," and Stuart said that "[the food bank is for] people that are suffering in worse circumstances.... I wouldn't consider myself as those kind of people." For some international students, food insecurity was perceived relative to their experiences back home. For example, Stuart explained, "We have different living standards compared to here," and when comparing his experience growing up versus living in Canada, he said he now "consider[s] [him]self kind of middle class." Yet others indicated that food insecurity was common among international students. For example, Emma stated that "some [may have] difficult times for food...that's really the norm of international students."

\section{Perceived Barriers to Food Security}

Students' discussions of the situations that precipitated shortages of food and money for food pointed to precarious finances as the major underlying barrier to food security. Experiences ranged from a single event or sudden income shock to consistent shortages over time. Students frequently cited insufficient or late provincial student loan instalments, high tuition rates, as well as exhaustion of their savings, which tended to occur near the end of the academic semester. Kelly explained the inaccuracy of cost-of-living estimates used to determine financial aid amounts, noting, "This whole [loan] system is built on [the assumption that] your parents are going to help pay for school," while Liam explained, "Just the way OSAP worked, I consistently never got enough." Students also struggled with housing costs, which were prioritized over more flexible food budgets; as Kiara explained, "Rent comes first."

Students enrolled in cooperative education expressed unique challenges related to extra costs and uncertainty of remuneration. Sophia explained that cobbling together her income from co-op and student loans was not always sufficient, and said that "[the provincial student financial assistance system] looks at your total income and lowers their loan," and that it was uncertain whether the income from her co-op job could cover the resulting shortfall for rent and food as well as tuition for the upcoming terms. Those identifying as international students also indicated unique financial challenges, such as high tuition fees and difficulties navigating the Canadian banking system and transferring money from their home countries.

\section{Attempts to Cope}

Students engaged in a variety of adjustment and adaptation strategies targeted at improving their financial security, which included applying for scholarships or bursaries, drawing on savings or government financial assistance, working one or more part-time jobs, borrowing food or money for food from family or friends, and participating in research for the honoraria. For example, Aaron relied on his friends for financial support during a period of food insecurity, and said, "I basically spoke to my friends and they offered to cover my rent," while Sophia's parents would purchase groceries for her when money was tight, explaining that, "When I'm with [my parents], they get my groceries, they don't let me pay." Other techniques were aimed at reducing the resources needed to access or purchase food, such as sharing food with roommates, lowering food expenditures by reducing meat purchases, buying in bulk, couponing or price-matching, shopping 
at discount grocery stores, accessing student discounts, and finding free food on campus. Stuart explained that during food shortages, he would "go to some seminars because they do have free food." As noted, some students also reported accessing the campus food bank. Kiara said, "A lot of students can't afford [food] 'cause school's expensive, so [the campus food bank] is nice to have, I guess sort of like a support there for food."

Many students distracted themselves with other priorities, so they were unable to dwell on their food situation. For example, Riya stated, "You tend to shift your focus toward school instead of answering to your body that it's hungry." Some students attempted to stretch food supplies. For example, Emma noted that she purchased large bags of noodles that would last several weeks, and Liam indicated that he stockpiled non-perishable foods that he accessed from the food bank to try to "conserve what [he had]" in case of future shortages.

However, attempts to adapt often fell short. For example, Alan explained that strategies such as finding free food on campus were "not really stable." Longer-term strategies could also not be relied upon consistently, as Liam explained, "I did things to prepare myself for a situation like this," such as saving money, regularly paying off credit cards to save space for food purchases, and anticipating a tax refund, but "everything I set up failed."

\section{Perceived implications for health and academic performance}

Despite the hesitation of some students to identify themselves as having experienced food insecurity (as illustrated by the normalization of food shortages and reliance on lowquality food, as well as their ambivalence regarding whether their situation necessitated accessing resources such as food banks), they described several ways in which inadequate food had affected their health. Physical manifestations, including hunger, fatigue, and changes in body weight, were frequently discussed. Kiara "felt hungry," and Isabel said that, during food shortages, "I was just tired constantly." Isabel was having trouble gaining weight to support her participation on a varsity sports team and explained, "I don't think I'm eating enough, and it's kind of due to the fact that I don't have that much from my kitchen to make." Alan stated he was "doing horribly" when it came to eating healthy food because "right now I'm focused on not going empty."

Consistently, mental health implications described during the interviews predominantly included feelings of anxiety and worry about the food supply; these worries existed on top of the stress they already experienced due to school responsibilities. Emma described the experience as "stress plus stress" and explained, "I got so many things to do on my todo list, and I still need to worry about my food." Kelly explained the impact of relying on poor quality foods, "You start a downward spiral, right? 'Cause you're stressed out...then you run out of more money, and then you don't feel good 'cause you're eating bad food."

Food insecurity was perceived as affecting academic performance, including focusing in class, studying, and completing assignments and exams. For example, Parth explained that running out of money for food "definitely hinders your full attention toward any particular thing that you're doing," and Aaron said, "It can be pretty difficult to work when you don't have, you know, proper food." Aryan felt that relying on low-cost foods hurt academic performance, and explained: 
A lot of my friends have a lot harder time at the end of the semester...[when] December, April rolls around, they're eating Mr. Noodles 'cause they ran out of all their money. So, obviously, that has a great effect on their school, or academic performance...you can't starve yourself through school.

Some had struggled to the point when they reduced their schooling to part-time or dropped out of school for a while. During his interview, Aaron was planning on reducing his course load in the following semester to free up more time to work. Kiara had taken time away from school to work because "school was just getting ridiculously expensive" and had recently returned to finish her degree.

\section{Other factors perceived to be associated with food access and consumption}

In addition to financial constraints that shaped shortages of food and reliance on poor quality foods, students discussed factors that influenced their food access and that were seen as exacerbating their inability to achieve healthy eating, including limited food literacy and food budgeting skills. Aspects of the food environment on campus and within the broader community were also perceived to influence food access. Students described the plethora of processed and fast foods available on campus and noted the need for a wider variety of healthier, low-cost options. The experience of social exclusion extended to the campus food environment; regarding the inaccessibility of the campus farmers' market, Sophia explained, "It's so expensive...there are posters about it everywhere going, 'Oh you know, you don't have to go off campus to buy healthy food,' it's just $\$ 1.50$ per zucchini." Some students cited the lack of facilities for reheating food as a barrier to consuming healthy and low-cost options brought from home.

The location of food outlets within the wider community was perceived to present barriers for students in terms of food access. Chain grocery stores, convenience stores, and prepared food outlets with high price points are easily accessible to areas with high student housing density, while discount grocery stores and farmers' markets are located further away and require lengthy trips on public transportation. Kelly described her area of residence as being problematic, saying, "So many students live there, so we always sort of wonder why they don't have a grocery store near us." Students reported that the ease of access to prepared foods resulted in their frequent purchase. Riya explained:

You're limited to the places or the food areas offered around you...it's bad too, because [grocery stores] typically have cheaper food...when instead you could just fill your stomach with something close by. It just ends up being the poorer choices I guess.

Many students placed importance on culturally relevant foods but experienced barriers in accessing and/or affording them. Vivian noted, "I have to go back [to my hometown] just to...get the grocery items I want." Although some culturally appropriate food markets in the area were noted, students explained that the prices were prohibitive. However, in some cases, the trade-off between the high prices of imported cultural foods versus going without was deemed worth it. For example, as an international student with few friends living locally, Emma indicated she took great comfort in being able to eat the foods she was familiar with, and so she paid high prices to get what she wanted. Other consider- 
Food Insecurity in Higher Education / M. Maynard, S. B. Meyer, C. M. Perlman, \& S. I. Kirkpatrick 140

ations, including a commitment to environmental sustainability, also took a backseat to getting something to eat. For example, Parth wanted to purchase foods he perceived as environmentally friendly, but explained, "organic [food] versus you still don't have money for normal groceries."

\section{Discussion}

The findings of this study indicate that food insecurity among post-secondary students is a manifestation of insufficient financial resources and is perceived to have serious implications for their health and academic success. Indeed, students described an ongoing and relentless process of trying to manage and adapt to their food situation and the anxiety that accompanied it, experiences that were borne out by their responses to the HFSSM, which is an established measure of household food security (Bickel et al., 2000). Students reported experiences that coincided with the degree of food insecurity they had experienced; for example, those who reported indications of living in moderate or severely food-insecure households in the past 12 months described reducing the size of meals they ate during food shortages, while those who had experienced any level of food insecurity, including marginal, reported feelings of stress or worry about running out of money for food. Students' discussions of their struggles to access adequate food also revealed experiences that were not captured by the HFSSM, such as feelings of ambivalence toward the situation. For example, comments regarding the use of food banks suggested a strategy of distancing oneself from having experienced food insecurity, consistent with attempts to normalize food shortages and reliance on low-quality food as a typical student experience, while at the same time recognizing negative implications.

Some aspects of the experience seem consistent with Alaimo's (2005) conceptual model and the literature that informed it, including a preoccupation with the food supply, feelings of powerlessness and lack of control, and desire for independence and financial stability (Hamelin et al., 2002). Students were reluctant to rely on financial help, especially from family members. Students' desire to not be a burden on their families can be compared to the behaviours of children living in food-insecure households. For example, Fram et al. (2011) found that children and adolescents attempted to manage food insecurity on behalf of their families by eating less without being asked and trying to supplement their parents' income via part-time jobs.

Other populations struggling with food insecurity have also described making "tradeoffs" or "juggling" financial priorities, including food, housing, and debt payments (Hamelin et al., 2002). Similarly, the strategies students used to attempt to supplement and stretch available resources, including accessing free food, echo those reported in other food-insecure populations (Hamelin et al., 2002). The utility of such strategies for forestalling experiences of food insecurity is likely to be limited in the face of precarious finances.

In this sample, the occurrence of food shortages was reported to most frequently coincide with the end of the academic term, when loan payments ran short. Munro et al. (2013) also found that food-insecure students in South Africa were more likely to experience hunger at the end of the semester compared to the beginning, consistent with research among other low-income populations that suggests a worsening of food security with declining financial resources and an increased length of time since the last financial influx (Hamelin et al., 2002; Tarasuk, McIntyre, \& Li, 2007). 
The compromises in quality of food shared by students in this study also align with Alaimo's (2005) model and the few studies that have examined student food insecurity, health, and academic performance (Farahbakhsh et al., 2015; Gallegos et al., 2013; Maroto et al., 2014; Patton-Lopez et al., 2014). Indeed, food insecurity has been associated with poor diet among post-secondary students (Gallegos et al., 2013), a connection noted by students in the research described here who reported resorting to cheap, low-quality foods when money was tight. Participants in former research also discussed implications in terms of stress and anxiety, as well as ramifications for their participation in social events. In more detailed cross-sectional work examining associations between food insecurity and mental health among students in the Midwestern U.S., Bruening et al. (2016) found that those who reported food insecurity had nearly three times the odds of experiencing depression, and nearly two times the odds of having an anxiety disorder, compared to food-secure students. Worryingly, work by Gallegos et al. (2013) found that food-insecure students were three times as likely to have deferred their studies as a result of financial hardship compared to food-secure students.

A common issue precipitating food shortages was the mismatch between student loan amounts and tuition and living costs, similar to the experiences of Canadians who rely on social assistance (Tarasuk et al., 2012). The levels of financial assistance allotted to students to support post-secondary studies are based on assumptions regarding parental financial support, as well as the contribution of savings from summer employment (Statistics Canada, 2011). However, students in this study suggested that parental support is not universally available or sufficient due to other demands on families' resources. Earnings from summer jobs and cooperative education positions can also vary and be unpredictable.

The existing evidence thus suggests the need for rethinking tuition rates (averaging about $\$ 6,400$ per year in 2016-17) (Statistics Canada, 2016) and funding systems to better reflect the financial realities of students (Burley \& Awad, 2015) and ensure that higher education does not become a luxury available only to some. Tuition fees have already been frozen in Newfoundland and Labrador and in Alberta, a move that could be considered elsewhere as a stopgap to improve affordability while additional options are weighed and evaluated; for example, the Ontario Student Grant provides free tuition, on average, for students whose family income is less than $\$ 50,000$ (though the Ministry of Advanced Education and Skills Development notes that not all students who meet this requirement have sufficient financial need to receive the equivalent of free tuition) (Government of Ontario Ministry of Advanced Education and Skills Development, 2017). Attention should also be paid to mandatory fees levied on students to support student associations, new infrastructure, and other costs. Importantly, tuition and associated costs have implications for well-being now and into the future, with the average debt load for graduating students receiving funding through the Canada Student Loans Program totalling approximately $\$ 28$,000 in 2013 (Burley \& Awad, 2015). In addition to attention to the adequacy of assistance levels, more stable and predictable installment structures for financial aid could perhaps help to alleviate shortfalls at the end of the academic term, as well as reduce student anxiety about such shortfalls. Students also drew attention to barriers posed by the food environment and their limited food literacy and food skills; yet addressing these factors without also addressing financial security is unlikely to alleviate food insecurity, which speaks to the need for a comprehensive approach. 
The location of the study (a university in southwestern Ontario) is unique in terms of the breadth of cooperative education, though many colleges and universities across Canada include work placements or internships in undergraduate and graduate degree curricula (Rodriguez, Zhao, \& Ferguson, 2016). Co-op programs have been found to enhance self-efficacy and confidence and contribute to student retention (Drewery, Nevison, \& Pretti, 2016; Newhook, 2016). However, although our sample is small, students expressed that uncertainty regarding co-op income and expenses exacerbated financial instability. A review of possible unintended consequences of cooperative education programs could shed light on strategies for better supporting the financial well-being of participants. International students also appear to be particularly vulnerable to financial precarity and food insecurity due to the cost of living (Calder \& Burns, 2016; Hanbazaza et al., 2016), perhaps not surprisingly given that the average international undergraduate tuition, at \$24,000 for 2016-17, is four times the rate of domestic tuition (Statistics Canada, 2016). This suggests the need for universities to consider the broader ramifications of increasing recruitment efforts to draw students from outside of Canada.

The findings of this study should be considered in light of a number of factors. Despite a small sample size, this study is unique in its mixed-methods exploration of the experience of food insecurity among post-secondary students and will therefore inform further research. A key strength includes recruitment of participants outside of a food bank to allow for a more comprehensive understanding of the problem and its manifestations. The recruitment strategy was intended to achieve in-depth perspectives of a general sample of students, including domestic and international students, as well as those in cooperative education, given the extensive presence of this program on the campus. However, this sample is not purported to be representative of nor generalizable to the wider university student body, and it should be noted that a few students reported participation in on-campus studies as a coping strategy to deal with insufficient finances, potentially indicating selection bias. Further, the study was not designed to elucidate experiences of food insecurity among students in relation to a broader range of factors, such as race and ethnicity. Recent research suggests that risk of food insecurity among U.S. students may differ by racial background (Miles et al., 2017; Payne-Sturges et al., 2017), suggesting the need for additional research to delve deeper into intersections with race, ethnicity, gender, and other factors that may play a role in vulnerability to and experiences of food insecurity (Bauer, 2014). Future investigations should also consider experiences of food insecurity among those who have traditionally faced barriers accessing post-secondary education in Canada, such as Indigenous students. Additionally, three participants did not complete the HFSSM, which prevents a fuller understanding of the degree of food insecurity they experienced in the prior 12 months, though experiences shared during the interviews were consistent with food insecurity. Further, the HFSSM-Adult may be limited in its ability to accurately measure food insecurity among a student population.

In sum, the findings suggest that food insecurity is a serious issue among post-secondary students and highlight the need to challenge the starving student ideology, which normalizes the lack of access to healthy food during higher education. Students in this study, while on the one hand normalizing and attempting to adapt to their experiences, also expressed stress, anxiety, and frustration in response to inadequate finances for food. Furthermore, they described the negative implications of their experiences of food anxi- 
ety and shortages for their health and academic success. While the redistribution of food waste has recently been discussed as an adequate policy solution to food insecurity, there have been many calls for action to move beyond the provision of emergency food to address the root causes of food insecurity in Canada; proposed actions target the adequacy of minimum wages, employment, and social assistance rates, among other policies and programs impacting upon financial well-being (McIntyre, Patterson, Anderson, \& Mah, 2017; Tarasuk et al., 2012; Tiessen, 2015; Wakefield, Fleming, Klassen, \& Skinner, 2012). Although further research is needed to more fully characterize the extent and implications of food insecurity among post-secondary students, it seems clear that strategies to alleviate food insecurity among all Canadians must also consider tuition rates and postsecondary loan systems.

\section{Acknowledgements}

The authors are grateful to Marc Lamoureux for his assistance with French translation.

\section{References}

Alaimo, K. (2005). Food insecurity in the United States: An overview. Topics in Clinical Nutrition, 20(4), 281-298. Retrieved from http://journals.lww.com/ topicsinclinicalnutrition/pages/default.aspx

Bauer, G. R. (2014). Incorporating intersectionality theory into population health research methodology: Challenges and the potential to advance health equity. Social Science and Medicine, 110, 10-17. https://doi: 10.1016/j.socscimed.2014.03.022

Bickel, G., Nord, M., Price, C., Hamilton, W., \& Cook, J. (2000). Guide to measuring household food security (revised ed.). Alexandria, VA: U.S. Department of Agriculture, Food and Nutrition Service.

Briefel, R. R., \& Woteki, C. E. (1992). Development of food sufficiency questions for the third national health and nutrition examination survey. Journal of Nutrition Education, 24(1), 24S-28S. https://doi.org/10.1016/Soo22-3182(12)80134-8

Bruening, M., Argo, K., Payne-Sturges, D., \& Laska, M.N. (2017). The struggle is real: a systematic review of food insecurity on postsecondary campuses. Journal of the Academy of Nutrition \& Dietetics, 117(11), 1767-1791. Available from: http://dx.doi.org/10.1016/j. jand.2017.05.022

Burley, G., \& Awad, A. (2015). The impact of student debt. Ottawa, ON: Canadian Federation of Students. Retrieved from http://cfs-fcee.ca/resources/policy-papers-andsubmissions/

Calder, M. J., \& Burns, K. K. (2016). International students attending Canadian universities: Their experiences with housing, finances, and other issues. Canadian Journal of Higher Education, 46(2), 92-110. Retrieved from http://journals.sfu.ca/cjhe/ index.php/cjhe/index

Campbell, C. C. (1991). Food insecurity: A nutritional outcome or a predictor variable? The Journal of Nutrition, 121(3), 408-415. https://doi.org/10.1093/jn/121.3.408 
Campbell, C. C., \& Desjardins, E. (1989). A model and research approach for studying the management of limited food resources by low income families. Journal of Nutrition Education, 21(4), 162-171. https://doi.org/10.1016/Soo22-3182(89)80052-4

Chaparro, M. P., Zaghloul, S. S., Holck, P., \& Dobbs, J. (2009). Food insecurity prevalence among college students at the University of Hawai'i at Mānoa. Public Health Nutrition, 12(11), 2097-2103. https://doi.org/10.1017/S1368980009990735

Chilton, M., \& Booth, S. (2007). Hunger of the body and hunger of the mind: African American women's perceptions of food insecurity, health and violence. Journalof Nutrition Education and Behavior, 39(3), 116-125. https://doi.org/10.1016/j.jneb.2006.11.005

Coleman-Jensen, A., Rabbitt, M. P., Gregory, C., \& Singh, A. (2015). Household food security in the United States in 2014, ERR-194. U.S. Department of Agriculture, Economic Research Service. Retrieved from https://www.ers.usda.gov/webdocs/ publications/45425/53740_err194.pdf?v=42515

Connell, C. L., Lofton, K. L., Yadrick, K., \& Rehner, T. A. (2005). Children's experiences of food insecurity can assist in understanding its effect on their well-being. The Journal of Nutrition, 135(7), 1683-1690. Retrieved from https://www.ncbi.nlm.nih.gov/ pubmed $/ 15987850$

Creswell, J. W. (2014). Research design: Qualitative, quantitative, and mixed methods approaches (4th ed.). Thousand Oaks, CA: SAGE Publications.

Drewery, D., Nevison, C., \& Pretti, T. J. (2016). The influence of cooperative education and reflection upon previous work experiences on university graduates' vocational selfconcept. Education + Training, 58(2), 179-192. https://doi.org/10.1108/ET-06-20150042

Farahbakhsh, J., Ball, G. D. C., Farmer, A. P., Maximova, K., Hanbazaza, M., \& Willows, N. D. (2015). How do student clients of a university-based food bank cope with food insecurity? Canadian Journal of Dietetic Practice and Research, 76(4), 200-204. https://doi.org/10.3148/cjdpr-2015-020

Fram, M.S., Frongillo, E.A., Jones, S.J., Williams, R.C., Burke, M.P., DeLoach, K.P., \& Blake, C.E. (2011). Children are aware of food insecurity and take responsibility for managing food resources. The Journal of Nutrition, 141(6), 1114-1119. https://doi. org/10.3945/jn.110.135988

Gaines, A., Robb, C. A., Knol, L. L., \& Sickler, S. (2014). Examining the role of financial factors, resources and skills in predicting food security status among college students. International Journal of Consumer Studies, 38(4), 374-384. http://dx.doi.org/10.1111/ ijcs.12110

Gallegos, D., Ramsey, R., \& Ong, K. W. (2013). Food insecurity: Is it an issue among tertiary students? Higher Education, 67(5), 497-510. https://doi.org/10.1007/s10734013-9656-2

Government of Ontario, Ministry of Advanced Education and Skills Development. (2017). FAQs About the New Ontario Student Assistance Program (OSAP). Retrieved from https://www.ontario.ca/page/osap-ontario-student-assistance-program 
Hamelin, A. M., Beaudry, M., \& Habicht, J. P. (2002). Characterization of household food insecurity in Quebec: Food and feelings. Social Science and Medicine, 54(1), 119132. Retrieved from https://www.ncbi.nlm.nih.gov/pubmed/11820676

Hanbazaza, M., Ball, G. D. C., Farmer, A., Maximova, K., \& Willows, N. D. (2016). Filling a need: Sociodemographic and educational characteristics among student clients of a university-based campus food bank. Journal of Hunger \& Environmental Nutrition, 11(6) 1-9. https://doi.org/10.1080/19320248.2015.1128864

Harden, J. (2017). The case for renewal in post-secondary education. Retrieved from The Canadian Centre for Policy Alternatives website: https://www.policyalternatives.ca/ publications/reports/case-renewal-post-secondary-education

Health Canada. (2007). Canadian community health survey, cycle 2.2, nutrition (2004): Income-related household food security in Canada. Ottawa, ON: Health Canada. Retrieved from http://www.hc-sc.gc.ca/fn-an/alt_formats/hpfb-dgpsa/pdf/surveill/ income_food_sec-sec_alim-eng.pdf

Hughes, R., Serebryanikova, I., Donaldson, K., \& Leveritt, M. (2011). Student food insecurity: The skeleton in the university closet. Nutrition and Dietetics, 68, 27-32. https://doi.org/10.1111/j.1747-0080.2010.01496.x

Layder, D. (1998). Sociological practice: Linking theory and social research (1st ed.). London, England: SAGE Publications.

Maroto, M. E., Snelling, A., \& Linck, H. (2014). Food insecurity among community college students: Prevalence and association with grade point average. Community College Journal of Research and Practice, 39(6), 515-526. https://doi.org/10.1080/106 68926.2013.850758

McIntyre, L., Patterson, P.B., Anderson, L.C., \& Mah, C.L. (2017). A great or heinous idea?: Why food waste diversion renders policy discussants apoplectic. Critical Public Health, 27(5), 566-76. http://dx.doi.org/10.1080/09581596.2016.1258455

Miles, R., McBeath, B., Brockett, S., \& Sorenson, P. (2017) Prevalence and predictors of social work student food insecurity. Journal of Social Work Education, 53(4), 651-63. https://doi.org/10.1080/10437797.2017.1299062

Munro, N., Quayle, M., Simpson, H., \& Barnsley, S. (2013). Hunger for knowledge: Food insecurity among students at the University of KwaZulu-Natal. Perspectives in Education, 31(4), 168-179. Retrieved from https://www.researchgate.net/publication/277291353_ Hunger_for_knowledge_Food_insecurity_among_students_at_the_University_of_ KwaZulu-Natal

Newhook, R. (2016). Are university co-operative education students safe? Perceptions of risk to students on work terms. Canadian Journal of Higher Education, 46(1), 121137. Retrieved from http://journals.sfu.ca/cjhe/index.php/cjhe/article/view/186042

Patton-Lopez, M. M., Lopez-Cevallos, D. F., Cancel-Tirado, D. I., \& Vazquez, L. (2014). Prevalence and correlates of food insecurity among students attending a midsize rural university in Oregon. Journal of Nutrition Education and Behavior, 46(3), 209-214. https://doi.org/10.1016/j.jneb.2013.10.007 
Payne-Sturges, D. C., Tjaden, A., Caldeira, K. M., Vincent, K. B., \& Arria, A. M. (2017). Student hunger on campus: Food insecurity among college students and implications for academic institutions. American Journal of Health Promotion, 32(2), 1-6. https://doi. org/10.1177/0890117117719620

Radimer, K. L., Olson, C. M., Greene, J. C., Campbell, C. C., \& Habicht, J. P. (1992). Understanding hunger and developing indicators to assess it in women and children. Journal of Nutrition Education, 24(1), 36S-44S. https://doi.org/10.1016/Soo223182(12)80137-3

Richardson, T., Elliott, P., \& Roberts, R. (2013). The relationship between personal unsecured debt and mental and physical health: A systematic review and metaanalysis. Clinical Psychology Review, 33(8), 1148-1162. https://doi.org/10.1016/j. cpr.2013.08.009

Rodriguez, C., Zhao, J., \& Ferguson, S. J. (2016). Insights on Canadian society: Co-op participation of college and bachelor's graduates, Catalogue no.75-oo6-X. Statistics Canada. Retrieved from http://www.statcan.gc.ca/pub/75-006-x/2016001/ article/14692-eng.htm

Rose, D. (1999). Economic determinants and dietary consequences of food insecurity in the United States. The Journal of Nutrition, 129(2), 504S-505S. https://doi.org/10.1093/ jn/129.2.517S

Siefert, K., Heflin, C. M., Corcoran, M. E., \& Williams, D. R. (2001). Food insufficiency and the physical and mental health of low-income women. Women \& Health, 32(1-2), 159-177. https://doi.org/10.1300/Jo13v32no1

Silverthorn, D. (2016). Hungry for knowledge: Assessing the prevalence of student food insecurity on five Canadian campuses. Toronto, ON: Meal Exchange. Retrieved from http://mealexchange.com

Statistics Canada.(2011).Education indicatorsin Canada: Spending on postsecondary education, Catalogue no. 81-599-X, no. 7. Ottawa, ON: Statistics Canada. Retrieved from http://www.statcan.gc.ca/pub/81-599-x/81-599-x2011007-eng.htm

Statistics Canada. (2013). Canadian community health survey-Mental health (CCHS) [Data file]. Retrieved from http://www23.statcan.gc.ca/imdb/p2SV. pl? Function $=$ getSurvey\&SDDS $=5015$

Statistics Canada. (2014, September 11). University tuition fees, 2014/2015. The Daily. Retrieved from http://www.statcan.gc.ca/daily-quotidien/140911/dq140911b-eng.htm

Statistics Canada. (2016, September 7). Tuition fees for degree programs, 2016/2017. The Daily. Retrieved from http://www.statcan.gc.ca/daily-quotidien/160907/ dq160907a-eng.htm

Stuff, J. E., Casey, P. H., Szeto, K. L., Gossett, J. M., Robbins, J. M., Simpson, P. M., Bogle, M. L. (2004). Household food insecurity is associated with adult health status. Community and International Nutrition, 134(January), 2330-2335.

Tarasuk, V., McIntyre, L., \& Li, J. (2007). Low-income women's dietary intakes are sensitive to the depletion of household resources in one month. The Journal of Nutrition, 137(8), 1980-1987. https://doi.org/10.1093/jn/137.8.1980 
Tarasuk, V., Mitchell, A., \& Dachner, N. (2012). Household food insecurity in Canada 2012. Toronto, ON: Food Insecurity Policy Research (PROOF). Retrieved from http:// proof.utoronto.ca/wp-content/uploads/2014/05/Household_Food_Insecurity_in_ Canada-2012_ENG.pdf

Tiessen, K. (2015). Raising the bar, revisiting the benchmark question for Ontario's minimum wage. Toronto, ON: Canadian Centre for Policy Alternatives, Ontario Office. https://doi.org/10.1126/science.1257891

Wakefield, S., Fleming, J., Klassen, C., \& Skinner, A. (2012). Sweet charity, revisited: Organizational responses to food insecurity in Hamilton and Toronto, Canada. Critical Social Policy, 33(3), 427-50. https://doi.org/10.1177/0261018312458487

Weinreb, L., Wehler, C., Perloff, J., Scott, R., Hosmer, D., Sagor, L., \& Gundersen, C. (2002). Hunger: Its impact on children's health and mental health. Pediatrics, 110(4), 1-9. https://doi.org/10.1542/peds.110.4.e41

\section{Contact Information}

Merryn Maynard

Meal Exchange

merrynsmaynard@gmail.com

Merryn Maynard is a graduate of the School of Public Health and Health Systems (MSc.) at the University of Waterloo. In her current role as Program and Operations Coordinator at the non-profit organization Meal Exchange, she works with post-secondary students, academics, and administrators to improve food security on Canadian campuses. Merryn volunteers with the Food Secure Canada Youth Caucus and as an executive member of the Toronto Youth Food Policy Council. Her interests focus on healthy public policy and how the food system affects health equity among young people in Canada.

Dr. Samantha Meyer is an Associate Professor in the School of Public Health and Health Systems at the University of Waterloo. Her primary areas of inquiry relate to the challenges public health agencies face in meeting targets for health service access and use in Canada, Australia (via her adjunct appointment at Flinders University), and internationally. Her current major research focus is the critical issue of trust in healthcare and its implications for preventative service utilization. Specifically, she is interested in the role of trust in Canadians' use of immunization and cancer screening programs.

Dr. Perlman is an Assistant Professor in the School of Public Health and Health Systems at the University of Waterloo. He conducts health services and policy research to improve health systems for people with mental health conditions. Specific areas of focus include the evaluation of mental healthcare quality, geographic variations in supply and access to mental health services, design of screening and outcome measures, and the design of tools to support evidence-informed decision making. 
Dr. Sharon Kirkpatrick is a Registered Dietitian and is an Associate Professor in the School of Public Health and Health Systems at the University of Waterloo. Her research primarily focuses on understanding dietary patterns in populations and influences on these patterns, using a systems-thinking lens to consider the array of factors at play. Much of her work is aimed at improving methodologies for measuring diet to foster a robust evidence base on the influence of diet on health and the impact of interventions on diet. She has long-standing interests in nutrition and food access among marginalized populations. 